The INL is a

U.S. Department of Energy

National Laboratory

operated by

Battelle Energy Alliance

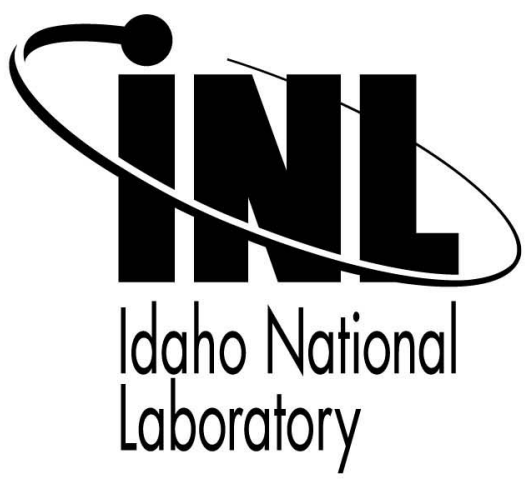

INL/CON-08-14272

PREPRINT

\section{Using Electronic Neutron Generators in Active Interrogation to Detect Shielded Fissionable Material}

\section{Nuclear Science \\ Symposium/Medical Imaging Conference}

\author{
David L. Chichester
}

\author{
October 2008
}

This is a preprint of a paper intended for publication in a journal or proceedings. Since changes may be made before publication, this preprint should not be cited or reproduced without permission of the author. This document was prepared as an account of work sponsored by an agency of the United States Government. Neither the United States Government nor any agency thereof, or any of their employees, makes any warranty, expressed or implied, or assumes any legal liability or responsibility for any third party's use, or the results of such use, of any information, apparatus, product or process disclosed in this report, or represents that its use by such third party would not infringe privately owned rights. The views expressed in this paper are not necessarily those of the United States Government or the sponsoring agency. 


\title{
Using Electronic Neutron Generators in Active Interrogation to Detect Shielded Fissionable Material
}

\author{
David L. Chichester, Senior Member, IEEE, and Edward H. Seabury
}

\begin{abstract}
Experiments have been performed at Idaho National Laboratory to study methodology and instrumentation for performing neutron active interrogation die-away analyses for the purpose of detecting shielded fissionable material. Here we report initial work using a portable DT electronic neutron generator with a ${ }^{3} \mathrm{He}$ neutron detector to detect shielded fissionable material including enriched uranium and reactor grade plutonium. Measurements have been taken of bare material as well as of material hidden within a large plywood cube. Results from this work have demonstrated the efficacy of the die-away neutron measurement technique for quickly detecting the presence of special nuclear material hidden within plywood shields by analyzing the time dependent neutron signals in-between neutron generator pulses. Using a DT electronic neutron generator operating at $300 \mathrm{~Hz}$ with a yield of approximately $0.36 \times 10^{8}$ neutrons per second, $2.2 \mathrm{~kg}$ of enriched uranium hidden within a $61 \mathrm{~cm} \times 61 \mathrm{~cm} \times 71 \mathrm{~cm}$ volume of plywood was positively detected with a measurement signal 2sigma above the passive background within 1 second. Similarly, for a 500 second measurement period a lower detection limit approaching the gram level could be expected with the same simple set-up.
\end{abstract}

\section{INTRODUCTION}

$\mathrm{T}$ HERE is a pressing need for a portable system capable of detecting the presence of shielded fissionable material, special nuclear material (SNM), in moderate sized containers. This capability is needed in order to have a rapidly deployable tool for field-response emergency situations to either a) perform primary field assays to identify the presence of SNM or b) serve as a secondary assessment tool to confirm or dismiss field assays of suspected SNM material. Techniques for performing passive screening to detect SNM have been described in the literature, a good survey of the topic has been presented by Fetter et al.[1] The principle materials of concern here are weapons grade uranium $(\mathrm{WgU})$ and weapons grade plutonium $(\mathrm{WgPu})$. WgU presents the most difficult detection challenge because it does not inherently emit either a large number of photons or neutrons; that is to say, its passive radiation emission signature is weak and difficult to measure. $\mathrm{WgPu}$ is generally a less difficult material to detect because it possess a naturally elevated neutron emission signature with an accompanying gamma-ray signature due to neutron

Manuscript received October 20, 2008. Idaho National Laboratory is operated for the U.S. Department of Energy by Battelle Energy Alliance under DOE contract DE-AC07-05ID14517. This work was supported by INL Laboratory Directed Research and Development funding.

D. L. Chichester (telephone: 208-526-8920, e-mail: David.Chichester@INL.gov) and E. H. Seabury (e-mail: Edward.Seabury@INL.gov) are with Idaho National Laboratory, Idaho Falls, ID 83415 USA. interactions in surrounding media; also, its inherent gammaray signature is strong without shielding.

Gamma-ray spectrometers are the most commonly used tool for detecting SNM.[2] However, since these instruments are based upon low-energy gamma-ray spectroscopy they are generally ineffectual when searching for moderate quantities of SNM, especially $\mathrm{WgU}$, hidden within mid- to high-Z shields such as steel or lead. For example, with less then 2 inches of lead the passive gamma-ray signatures from $\mathrm{WgU}$ (not reprocessed) are essentially unmeasurable.[3] Passive neutron detectors are also used for SNM detection, including systems using gross-neutron counting and systems examining neutron multiplicity characteristics.[4] Noting that $1 \mathrm{~kg}$ of $\mathrm{WgU}$ will generate roughly 1.6 neutrons per second [1], detection of $\mathrm{WgU}$ using passive neutron counting is obviously a difficult measurement to perform and moderate amounts of external shielding can be used to make detection in reasonable counting periods very challenging. Detection of modest amounts of $\mathrm{WgPu}$, with an inherent neutron source intensity of approximately 56,000 neutrons per second per kilogram of material [1], is easier to perform using neutron detectors than photon detectors and more difficult to shield within modest sized-containers. Of course, even without any neutron shielding passive neutron measurement techniques are not easily and quickly able to provide a positive identification of SNM in some situations, e.g. confirmation of plutonium versus a legitimate shipment of a commercial neutron source.

In our current work at Idaho National Laboratory (INL) we are performing research to examine the use of active neutron interrogation to detect, characterize, and quantify hidden, shielded fissionable material. Using an external neutron radiation source to probe a suspect SNM-containing object produces additional SNM signatures, generally stronger and less ambiguous than the passive signatures, which can allow positive/negative determinations to be made quicker and with lower material detection limits than with passive screening alone.[5-17] The most commonly used active neutron interrogation techniques for SNM detection involve the use of electronic neutron generators (ENGs), which produce nearly monoenergetic fast neutrons at either 2.5 or $14.1 \mathrm{MeV}$, operating as pulsed neutron sources. For these measurements the ENGs generate short pulses of neutrons, ranging from 0.01 $\mathrm{ms}$ to $1 \mathrm{~ms}$, and typically pulse at frequencies on the order of $\sim 100 \mathrm{~Hz}$. During each ENG pulse neutrons enter the test object, or assembly, where they undergo elastic and inelastic scattering and are eventually lost due to either absorption, leakage, or fission if SNM is present.

In low- $Z$ assemblies the source neutrons are quickly downscattered to thermal energies within tenths of a millisecond but 
then slowly leak out within tens of milliseconds (depending upon material composition and assembly size). In high- $Z$ assemblies the fast neutrons injected from the ENG tend to escape the assembly rather than losing energy and staying inside; in these systems the fast neutron and thermal neutron population decay times are much faster. In an unshielded SNM-containing assembly (e.g. bare $\mathrm{U}$ in an empty box) the residual neutron population following the ENG pulse immediately decays to very low levels which are influenced by the surrounding environment including proximity to and composition of the floor, walls and ceiling if present. In either case, as the initial neutron population decreases in energy, and while the thermal neutron population is resident in the assembly, fission will occur in SNM if present. The timedynamics of the fission rate in an assembly are situation specific, influenced positively over time as the mean energy of the neutron population decreases towards energies where the fission cross-sections become higher, but influenced negatively over time due to neutron absorption and leakage out of the assembly, which reduce the overall neutron population. Fast neutron induced fission occurs in these cases also but the resultant prompt neutron production and delayedneutron production from fast fission are low and usually important only for bare, unshielded cases where thermal fission is minimal.

One category of active neutron interrogation relies on the measurement of radiation emissions from fission products created in an assembly.[5-8,10,11,15] These measurements can include the detection of gamma rays and/or neutrons and the technique has proven useful in many situations. One challenge with this technique is that the intensity of these post-fission 'delayed' signatures is not high, at least in comparison with the gamma-ray and neutron signatures originating directly from fission. A strong-point for measuring the delayed radiation signatures is that competing background signals are usually very low.

Another category of measurements, die-away analysis, involves the detection of neutrons shortly after the neutron pulse as the fast neutrons down-scatter in energy and then as the thermal neutron population in the assembly decays.[79,12-14,16,17] During this period fission is still occurring and detectors suited for measuring these fission signatures directly can be used. The intensity of these prompt fission signatures is much stronger than those from the fission products used in the delayed measurements. A challenge in performing die-away assessments is that the detectors used for these measurements must be simultaneously sensitive to the prompt signatures while remaining insensitive to the generic signatures emanating from the test object from benign neutron scattering, capture, and leakage. For neutron detection a detector that is insensitive to thermal neutrons, such as a cadmium shielded helium-3 proportional counter or a liquid scintillator, may be used to accomplish this. For gamma-ray detection a spectrometer or a high-threshold counter may be used.

While fission is occurring in an assembly more sophisticated measurements analyzing neutron multiplicity may also be performed. These measurements are highly fission specific and have very high signal to noise relationships; however, the overall sensitivity for these types of measurements is less than in basic neutron counting when comparable sized detector systems are used. Measurements may also be performed during the ENG pulse, which are sometimes called prompt or in-beam measurements, but these are challenging because of interferences from the ENG and because scattering inside the object are not easily accounted for.

Active interrogation may also be performed using highenergy bremsstrahlung, where $x$ rays exceeding the photofission thresholds for SNM are used to induce fission in an assembly rather than neutron-induced fission. It is worth noting, however, that photoneutrons ejected from non-SNM materials often make an important contribution to the total fission signature once they've down scattered to thermal energies. Photon active interrogation is a powerful technique and can often complement neutron interrogation in situations where neutron penetration into an assembly is low, and vice versa. However, the large size and complexity of the electron accelerators needed to generate adequate radiation fields precludes their use for portable applications.

This paper presents results from experiments conducted at INL using an ENG to perform active interrogation of lightlyshielded fissionable material. INL maintains an inventory of SNM, including uranium of varying enrichments and plutonium with varying ${ }^{239} \mathrm{Pu}$ isotopic purity, in multiple forms including metal plates and rods, alloyed metals, and oxides. The work took place inside INL's zero-power physics reactor (ZPPR) facility which allows for the safe and secure use of SNM in a controlled environment. The facility includes a large area suitable for active interrogation research using both ENGs and high-energy x-ray machines. It should be noted that the passive neutron background inside this facility, $24.1 \pm 0.2$ counts per second (cps) for the detectors used here, is significantly higher than Idaho Falls' natural neutron background of $0.984 \pm 0.032 \mathrm{cps}$ with the same detectors.

\section{THE EXPERIMENT}

Experiments were performed to measure the time dependent die-away neutron signature from a variety of test items in a bare configuration and when shielded with wood. A list of the test items is presented in Table I, they included enriched uranium (Item 1), depleted uranium (Item 2), a mixture of reactor grade plutonium and depleted uranium (Item 3 ), and tungsten (Item 4). The items were all in the form of multiple metal plates with dimensions of approximately $0.3 \mathrm{~cm} \times 5.1$ $\mathrm{cm} \times 10.2 \mathrm{~cm}(0.125$ in $\times 2$ in $\times 4$ in), the SNM plates were clad in a very thin shell of stainless steel. All test items were further encased within a rectangular protective aluminum canister, or "clamshell," measuring $69.8 \mathrm{~cm} \mathrm{x} 18.7 \mathrm{~cm}$ x 28.6 $\mathrm{cm}$ (2.75 in $\mathrm{x} 7.375$ in $\mathrm{x} 11.25$ in) in size with a walls approximately $0.6 \mathrm{~cm}$ thick. Plates were stacked upright, side by side in the center of the clamshells so that their longest dimension was aligned with and parallel to the clamshell's $18.7 \mathrm{~cm}$ dimension and their second largest dimension was aligned with and parallel to the $69.8 \mathrm{~cm}$ dimension. In all 
cases the flat, large base of the clamshell remained aligned parallel with the floor.

TABLE I

MATERIAL COMPOSITION OF THE TEST ITEMS $(\mathrm{kg})$

\begin{tabular}{ccccc} 
Component & $\begin{array}{c}\text { ITEM 1 } \\
\text { Enriched } \\
\text { Uranium }\end{array}$ & $\begin{array}{c}\text { ITEM 2 } \\
\text { Depleted } \\
\text { Uranium }\end{array}$ & $\begin{array}{c}\text { ITEM 3 } \\
\text { Reactor } \\
\text { Grade } \\
\text { Plutonium \& } \\
\text { Depleted } \\
\text { Uranium }\end{array}$ & ITEM 4 \\
\hline $\mathbf{W}$ & 0 & 0 & 0 & 2.0 \\
${ }^{235} \mathbf{U}$ & 2.011 & 0.004 & 0.008 & 0 \\
${ }^{238} \mathbf{U}$ & 0.145 & 1.965 & 3.862 & 0 \\
${ }^{239} \mathbf{P u}$ & 0 & 0 & 1.438 & 0 \\
${ }^{240} \mathbf{P u}$ & 0 & 0 & 0.545 & 0 \\
\hline
\end{tabular}

Measurements were taken with the clamshells unshielded and supported by a steel table, or hidden within a wood cube having a square base measuring $61 \mathrm{~cm} \times 61 \mathrm{~cm}$, with a height of $71 \mathrm{~cm}$. When sitting on the steel support table the material inside the clamshell was approximately $85 \mathrm{~cm}$ above the floor. The wood cube was comprised of eight separate wood cubes made from standard plywood, each measuring $30.5 \mathrm{~cm}$ (12 in) on a side and an adjustable wood drawer measuring $61 \mathrm{~cm} \mathrm{x}$ $61 \mathrm{~cm}$ square with a height of $10 \mathrm{~cm}$. Four plywood cubes were placed on the floor, then the wood drawer was placed on top of these, and then four more plywood cubes were placed on top of the drawer. The wood drawer was filled with movable planks of wood arranged in a way so that a hidden void large enough to hold a clamshell was made within the drawer. The planks could be rearranged to relocate the void to different positions within the drawer. For the experiments reported here the void was arranged at the front of the box (closest to the neutron generator), in the middle of the box, and at the rear of the box (farthest away from the neutron generator.) The set-up has the versatility to 'hide' the clamshell in 9 locations inside the wood drawer; positioning the wood drawer on the floor, in the middle, or on top of the plywood allows a total 27 void locations. Photos of a clamshell sitting on the steel support table and of a clamshell inside the wood cube are shown in Fig. 1.

An MP-320 electronic neutron generator (Thermo Scientific, Colorado Springs, CO, USA) producing $14.1 \mathrm{MeV}$ neutrons via the deuterium-tritium fusion reaction was used as the neutron source for these experiments.[18] It was operated with an average neutron yield of $(0.36 \pm 0.04) \times 10^{8}$ neutrons per second. Although capable of producing a higher neutron yield a lower output setting was used for these experiments to avoid saturating the neutron detector. The ENG was pulsed at a frequency of $300 \mathrm{~Hz}$ with a pulse width of $0.333 \mathrm{~ms}$ (a $10 \%$ duty cycle). The ENG was placed directly on a concrete floor, neutron emission from the generator occurred approximately $14 \mathrm{~cm}$ above the floor. When irradiating the bare clamshell the ENG was approximately $61 \mathrm{~cm}(24 \mathrm{in})$ in front of the materials inside; when irradiating the wood cube the ENG was approximately $15.2 \mathrm{~cm}(6 \mathrm{in})$ in front of the box.
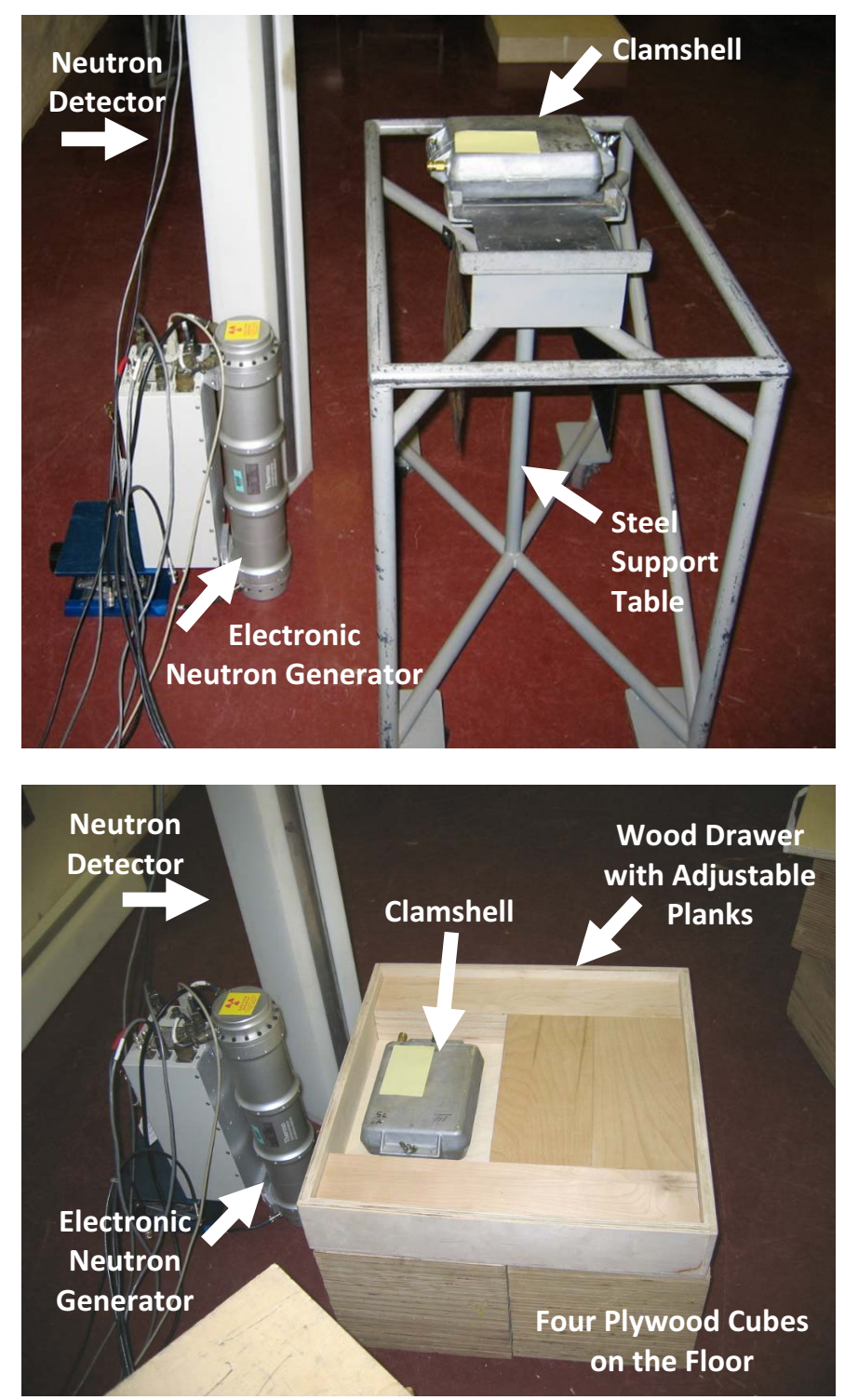

Fig. 1 (Top) Experimental arrangement for testing material in a bare clamshell, showing the relative orientation of the neutron generator, detector, and clamshell. (Bottom) Experimental arrangement for testing material in the hidden void of the wood cube, showing the relative orientation of the neutron generator, detector, and clamshell. For the experiments a wood lid was placed on top of the drawer, which was then covered with four additional wood cubes. In this image the clamshell is shown at the front of the box, closest to the neutron generator.

A $10 \mathrm{~atm}{ }^{3} \mathrm{He}$ proportional counter with a diameter of 2.54 $\mathrm{cm}(1 \mathrm{in})$ and an active length of $76.2 \mathrm{~cm}$ (30 in) was used in these experiments.[19] The detector was immediately surrounded by $2.54 \mathrm{~cm}$ (1 in) of plastic and then surrounded by cadmium and boron to absorb thermal neutrons. It has an intrinsic efficiency for fission neutrons from a ${ }^{252} \mathrm{Cf}$ source of approximately $5.9 \%$. The detector generates a TTL (transistor-transistor logic) data signal output when a neutron detection event occurs. The detector was oriented perpendicular to the ground, as shown in Fig. $1,15.2 \mathrm{~cm}$ (6 in) in front of the box, $30.5 \mathrm{~cm}$ (12 in) to the side of the ENG.

A multi-channel scaler (MCS) counting unit operated using a personal computer was used to collect data for 500 second periods. The start time for the MCS was taken directly 
from the MP-320 ENG as a TTL output. It took roughly 15 seconds for the ENG to reach the selected neutron yield when turned on; data collection was started as soon as the ENG reached this level, thus delayed neutron equilibrium was not achieved prior to the collection of data. Long-period drift in the output of the neutron generator which may have occurred during the day was not accounted for. Passive background data (BKD) was collected with and without the $\mathrm{Pu}$ (which had a high natural neutron activity), with and without the wood, using the MCS but with an external pulse generator set to 300 $\mathrm{Hz}$ in place of the ENG TTL pulse signal. At the beginning of the day an active background (Detector) response of the detector with the ENG pulsing but without the steel test stand or wood, was taken for use with measurements of the enriched uranium. A similar data set was taken at mid-day for use with the depleted uranium, reactor grade plutonium/depleted uranium mixture, and tungsten test items. This active background signal is plotted as "detector" in the plots below.

\section{RESULTS}

Neutron die-away time spectra from the four test items are presented in Fig. 2 through Fig. 5 below. In each figure the raw data from the MCS are shown for 500 seconds of collection a) with the ENG on when the sample is present, Signal (blue), b) data collected from the detector when the ENG was on but neither material nor the steel test stand nor any wood was present, Detector (red), and c) for passive background data taken in the area, $B K D$ (black).
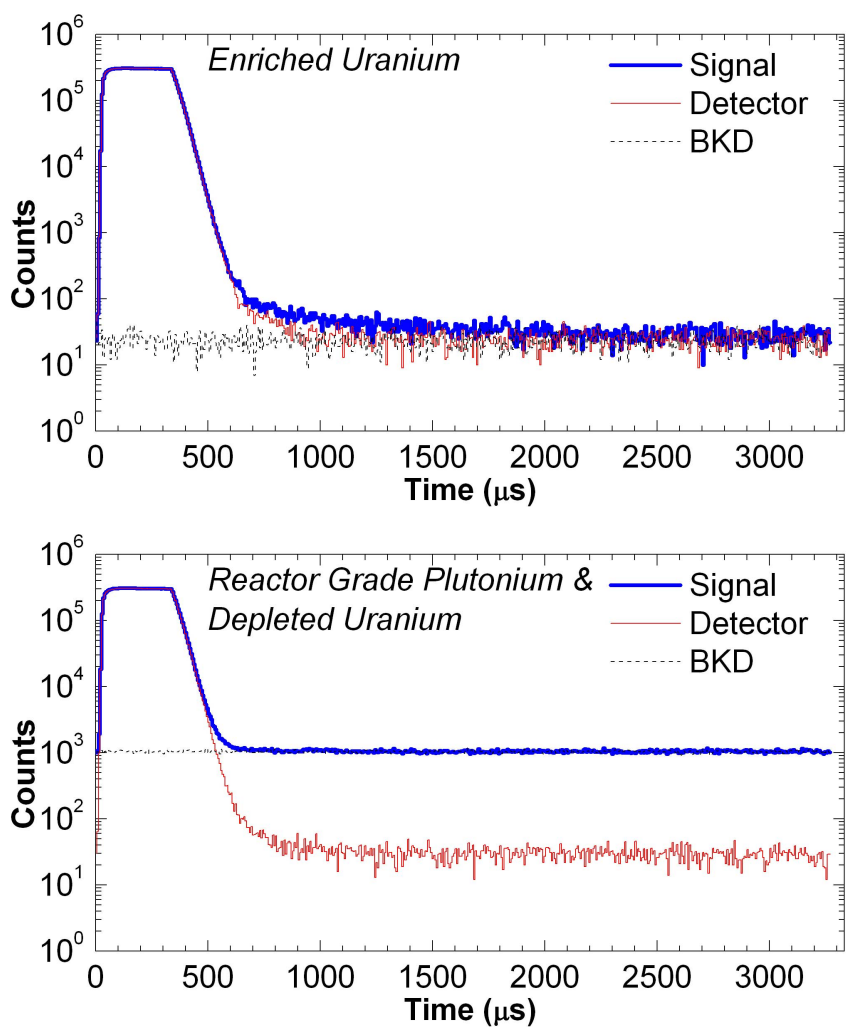

Fig. 2 Neutron die-away time spectra for enriched uranium (top) and the reactor grade plutonium/depleted uranium mixture (bottom) on the steel support table.
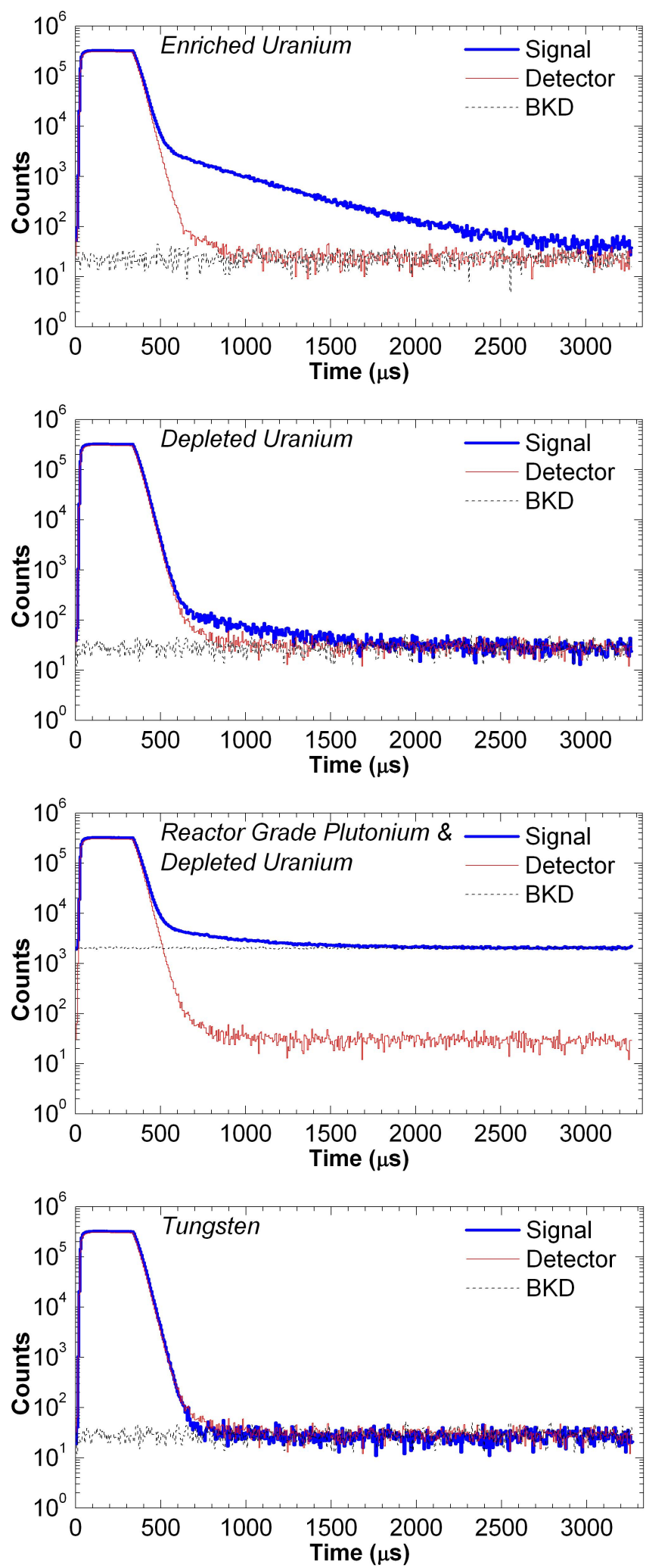

Fig. 3 Neutron die-away time spectra for enriched uranium (top), depleted uranium (second from top), reactor grade plutonium/depleted uranium mixture (second from bottom), and tungsten (bottom) located in the front of the wood shield cube. 

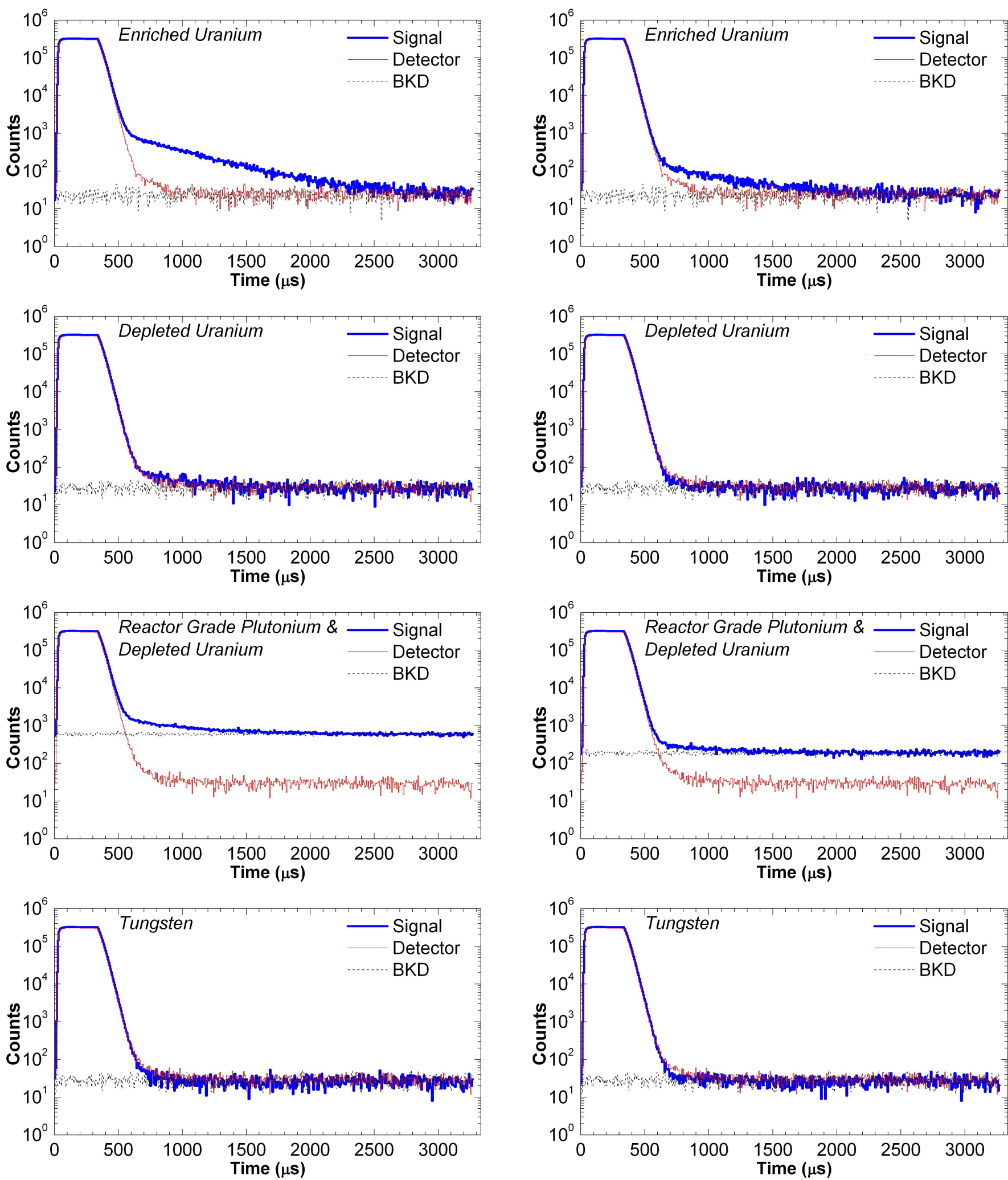

Fig. 4 Neutron die-away time spectra for enriched uranium (top), depleted uranium (second from top), reactor grade plutonium/depleted uranium mixture (second from bottom), and tungsten (bottom) located in the middle of the wood shield cube.

Fig. 5 Neutron die-away time spectra for enriched uranium (top), depleted uranium (second from top), reactor grade plutonium/depleted uranium mixture (second from bottom), and tungsten (bottom) located in the rear of the wood shield cube. 
As a simple estimate to evaluate the sensitivity of the dieaway measurements for the materials and geometry used here, the net number of counts (signal minus passive background) was determined over the period from $1000 \mu$ s to $3270 \mu$ s for each case. This data is presented in Table II. The start time of $1000 \mu$ s was arbitrarily chosen as a conservative time at which all transient signals from neutron scattering in the object, the room, and the detector have returned to background levels.

TABLE II

Net Die-Away Neutron Counts (Active Signal Minus Passive BACKGROUND) COLLECTED OVER 500 SECONDS

\begin{tabular}{|c|c|c|c|c|}
\hline Case & $\begin{array}{l}\text { Enriched } \\
\text { Uranium }\end{array}$ & $\begin{array}{l}\text { Depleted } \\
\text { Uranium }\end{array}$ & $\begin{array}{c}\text { ITEM } 3 \\
\text { Reactor Grade } \\
\text { Plutonium \& } \\
\text { Depleted } \\
\text { Uranium } \\
\end{array}$ & Tungsten \\
\hline No Shield & $3,309 \pm 142$ & & $665 \pm 862$ & \\
\hline Wood - Front & $68,302 \pm 292$ & $3,826 \pm 149$ & $63,683 \pm 1,228$ & $327 \pm 137$ \\
\hline Wood - Middle & $22,885 \pm 200$ & $1,439 \pm 141$ & $19,858 \pm 670$ & $123 \pm 136$ \\
\hline Wood - Rear & $3,880 \pm 143$ & $618 \pm 137$ & $4,449 \pm 371$ & $317 \pm 137$ \\
\hline
\end{tabular}

\section{DISCUSSION}

The neutron die-away signal intensity from the enriched uranium used here is very strong. It is interesting to compare the data for the enriched uranium with the delayed-neutron data presented by Moss et al. using test samples of a $5 \mathrm{~kg}$ sphere of similarly enriched uranium in a bare configuration, and when shielded by iron, lead, and polyethylene.[11] In particular it is worth noting that the neutron generator used in this reference is liquid-insulated (fluorinert FC-77), with several liters of fluid used in place of the low-density sulfur hexafluoride gas used in the MP-320, which may have slightly moderated the out going neutron spectrum and improved the induced fission rate versus that from an unmoderated spectrum. For those measurements the ENG to test item spacing was $100 \mathrm{~cm}$ (compared with approximately $50 \mathrm{~cm}$ for the tests reported here) and the test item to detector spacing was also $100 \mathrm{~cm}$ (again compared with approximately $50 \mathrm{~cm}$ for the tests reported here.) The detector used in the reference demonstrated a $20 \%$ intrinsic efficiency versus the $5.9 \%$ intrinsic efficiency of the detector used here, it also presented a larger solid angle than in the case shown here. Making some simple $1 / \mathrm{r}^{2}$ estimates for ENG / test item / detector spacing, accounting for fissile material mass, neutron generator yields $\left(0.5 \times 10^{7}\right.$ neutrons per second in the reference), and detector efficiencies, and neglecting detector solid angle differences, the measurement count rate date for the set-up presented here could be scaled, very roughly, by a factor of $\left(2^{2} \times 2^{2} \times(2.011 / 5) \times(0.36 / 0.5) \times(5.9 / 20)\right)^{-1}=0.732$ to allow comparisons with the Moss et al. data. Using this as a guide the advantage of performing die-away measurements over pure delayed-neutron measurements is seen.

For the bare uranium used here the scaled die-away signal is (6.6 cps x 0.732) $4.8 \mathrm{cps}$ versus $2.2 \mathrm{cps}$ from the Moss delayed-neutron data. At first glance the die-away signal would appear to be not much better than the delayed signal.
However, the presence of pre-moderating material (insulating liquid) in the ENG used for delayed neutron measurement is likely serving to significantly boost this signal over what would be expected in an unmoderated situation. A more comparable situation may exist for the shielded uranium case presented here with enriched uranium in the middle of the wood block, (45.8 cps x 0.732 ) $33.5 \mathrm{cps,}$, and the case where Moss et al. used $6.35 \mathrm{~cm}$ of polyethylene $(1.7 \mathrm{cps})$. In this case both interrogating neutron fields undergo significant moderation prior to interacting with the uranium and the dieaway signal is much larger than the delayed neutron signal. Based upon these observations, it is clear that a) a modest amount of local moderating material near the generator (in the Moss et al. data) makes a significant improvement in the measured material signature and $b$ ) under similar conditions the die-away signal can provide a more intense signature than the delayed neutron signal.

The net neutron count intensity values presented in Table II were determined starting from $\mathrm{t}=1000 \mu \mathrm{s}$. Examining Fig. 2 through Fig. 5 it is clear that this sacrifices a significant amount of valuable data. When a more careful evaluation of the detectors response is used up to twice as many counts can be recognized in some cases, particularly for the higher countrate scenarios. It has been suggested previously that using a thermal neutron sensitive neutron detector, in addition to the fast-neutron sensitive detector, can allow for a better determination of the count start time by examining the assembly's thermal neutron die-away characteristics.[14] Considering this concept in light of the data shown here it seems that this approach would indeed prove useful for improving die-away measurements of unknown objects.

One apparent discrepancy in the data is the repeatable but slightly high net neutron intensity observed for the nonfissionable tungsten test object. An explanation for this may be due to a small change in the intensity of the background between when the tungsten data was taken and when the background data used with the tungsten data was taken. Recognizing that the background neutron rate in the ZPPR area is elevated, several background measurements were taken over the day. The background rate at the end of the day was observed to be $26 \%$ higher than at the start of the day, which was due to the presence of the reactor grade plutonium during the afternoon measurements (when data with the depleted uranium, reactor grade plutonium and depleted uranium mixture, and tungsten were taken), which was not present during the morning when data with the enriched uranium was assessed. Although the $\mathrm{Pu}$ was on the far side of the room for the afternoon measurements, it is possible that when the wood was removed from the test area to take the afternoon background measurement data it was put in a position where it affected the local neutron background rate from the Pu. For reference, the on-contact neutron dose rate from the clamshell filled with reactor grade plutonium and depleted uranium was $0.30 \mathrm{mSv} / \mathrm{hr}$ (30 mrem/hr).

\section{SUMMARY}

Examining the results of Table II it is clear that the dieaway neutron measurement technique is an exceptionally 
powerful method for detecting the presence of shielded special nuclear material. For the cases studied here, using a low/mid$\mathrm{Z}$ shield such as wood, the presence of kilogram quantities of fissionable material including both enriched uranium and a mixture of reactor grade plutonium and depleted uranium could be easily confirmed within these small shield volumes in just a few seconds. Conversely, minimum detection limits approaching the gram level could likely be achieved in similar shield objects for comparable counting times to those used here. Detection of uranium hidden within this type of wooden shield would be very difficult or impossible using standard passive screening techniques.[3] Similarly, while the strong neutron emission rate from the reactor grade plutonium used in these experiments would be easily detectable using passive neutron screening, the active interrogation measurements demonstrated here would provide a useful secondaryconfirmation for screening a container declared as a legitimate shipment of a commercial neutron source, helping to eliminate any concern that the shipment was being used to mask a significant undeclared quantity of fissionable material.

\section{ACKNOWLEDGMENT}

We thank Mr. Bevin Brush for his assistance in coordinating these experiments and the ZPPR facility manager Mr. Eugene Perry and his support staff for their assistance in conducting these experiments.

\section{REFERENCES}

[1] Fetter, S., Frolov, V. A., Miller, M., Mozley, R., Prilutsky, O. F., Rodionov, S. N., and Sagdev, R. Z., "Detecting Nuclear Warheads," Sci. Global Sec. 1 (1990) 225-302.

[2] See for example the identiFINDER from ICx Technologies, Arlington, VA, USA (http://www.icx-radiation.com), the Detective from Ortec, Oak Ridge, TN, USA (http://www.ortec.com), or the Falcon 5000 from Canberra, Meriden, CT, USA (http://www.canberra.com).

[3] Doyle, J. E., Nuclear Safeguards, Security, and Nonproliferation, Butterworth-Heinemann, Oxford, U.K. (2008) pp. 511-512.

[4] See for example the IPRON-N Neutron Probe from Canberra, Meriden, CT, USA (http://www.canberra.com) or the Fission Meter from Ortec, Oak Ridge, TN, USA (http://www.ortec.com),

[5] McDonald, B. J., Fox, G. H., and Bremner, W. B., "Non-destructive Measurement of Plutonium and Uranium in Process Wastes and Residues," Technical Report IAEA-SM-201-61, IAEA, Vienna, Austria (1976) 589-597.

[6] Eccleston, G. and Menlove, H. O., "A Measurement System for High Enriched Spent Fuel Assemblies and Waste Solids," Nucl. Mat. Manag. 8 (1979) 344-355.

[7] Gozani, T., "Active Nondestructive Assay of Nuclear Materials," Technical Report NUREG/CR-0602, U.S. Nuclear regulatory Commission, Washington, D.C. (1981).

[8] "Passive Nondestructive Assay of Nuclear Materials," Reilly, D., Ensslin, N., and Smith Jr., H., Eds., Technical Report LA-UR-90-732, Los Alamos National Laboratory, Los Alamos, NM (1991).

[9] Bogolubov, Ye. P. et al., "Method and System Based on Pulsed Neutron Generator for Fissile Material Detection in Luggage," Nucl. Inst. Meth. Phys. Res. B 213 (2004) 439-444.

[10] Myers, W. L., et al., "Photon and Neutron Active Interrogation of Highly Enriched Uranium," AIP Conf. Proc. 769 (2005) 1688-1692.

[11] Moss, C. E., et al., "Portable Active Interrogation System," Nucl. Inst. Meth. Phys. Res. B 241 (2005) 793-797.
[12] Jordan, K. A. and Gozani, T., "Detection of ${ }^{235} \mathrm{U}$ in Hydrogenous Cargo with Differential Die-Away Analysis and Optimized Neutron Detectors," Nucl. Inst. Meth. Phys.. Res. A 579 (2007) 388-390.

[13] Jordan, K. A., Vujic, J., Phillips, E., and Gozani, T., "Improving Differential Die-Away Analysis Via the Use of Neutron Poisons in Detectors," Nucl. Inst. Meth. Phys. Res. A 579 (2007) 404-406.

[14] Jordan, K. A., Vujic, J., and Gozani, T., "Remote Thermal Neutron DieAway Measurements to Improve Differential Die-Away Analysis," Nucl. Inst. Meth. Phys. Res. A 579 (2007) 407-409.

[15] Hall, J. M., et al., "The Nuclear Car Wash: Neutron Interrogation of Cargo Containers to Detect Hidden SNM," Nucl. Inst. Meth. Phys. Res. B 261 (2007) 337-340.

[16] Jordan, K. A. and Gozani, T., "Pulsed Neutron Differential Die Away Analysis for Detection of Nuclear Materials," Nucl. Inst. Meth. Phys. Res. B 261 (2007) 365-368.

[17] Jordan, K. A., Gozani, T., and Vujic, J., "Differential Die-Away Analysis System Response Modeling and Detector Design," Nucl. Inst. Meth. Phys. Res. A 589 (2008) 436-444.

[18] Chichester, D. L., Simpson, J. D., and Lemchak, M., "Advanced Compact Accelerator Neutron generator Technology for Active Interrogation Field Work," J. Radioanal. Nucl. Chem. 271 (2007) 629637.

[19] Jones, J. L., et al., "Pulsed Photonuclear Assessment (PPA) Technique CY04 Year-end Progress Report," Technical Report INEEL/EXT-0502583, Idaho National Laboratory, Idaho Falls, ID (2005). 